\title{
Essential newborn care practices and associated factors among home delivered mothers in Damot pulasa Woreda, southern Ethiopia
}

Tesfaye Yitna Chichiabellu ${ }^{1 *}$, Baze Mekonnen², Feleke Hailemichael Astawesegn ${ }^{3}$, Birhanu Wondimeneh Demissie ${ }^{4}$ and Antehun Alemayehu Anjulo ${ }^{5}$

\begin{abstract}
Background: Globally 3.1 million children die each year in their neonatal period (first 28 days of life) according to World Health Organization (WHO) 2011 report. Half of these surprisingly occur within the first $24 \mathrm{~h}$ of delivery and $75 \%$ occur in the early neonatal period.

Methods: A community based cross-sectional study design was carried out from March 2016 to April, 2016 in Damot Pulasa district, Wolaita zone, Southern Ethiopia to assess selected essential newborn care practices and associated factors among home delivered mothers in Damot pulasa district. Data were entered into Epi Info version 3.5.1 and exported to SPSS version 20 software for analysis. Multiple logistic analyses were done to control possible confounding variable. A P-value less than 0.05 was taken as a significant association.

Result: The study showed that the prevalence of essential newborn care practice was $24 \%$. Multivariate logistic regression analysis revealed that variables like $A N C$ visit $(A O R=0.213, P=0.015, C l=0.102-0.446), P N C$ visit $(A O R=0.209$, $P=0.00, C l=0.110-0.399$ ), advice about essential newborn care practice ( $A O R=0.114, P=0.0001, C l=0.058-0.221$ ), urban areas women $(A O R=2, P=0.042, C l=1.024-3.693)$, planned pregnancy $(A O R=7, P=0.00, C l=3.732-11.813)$, and knowledge about newborn danger signs $(A O R=0.277, P=0.006, C l=0.110-0.697)$ were the independent predictors of ENBC practices.

Conclusion: Generally, coverage of essential newborn care practices was low. ANC visit, advice about ENBC, PNC visit, residence, planned pregnancy and knowledge about newborn danger signs were predictors of essential newborn care practice in the study area. Therefore, Health facilities should enhance linkage with health posts to increase ANC and PNC service utilization. Health extension workers should also promote and give health education about pre-lacteal feeding, early bathing, planned pregnancy, newborn danger signs and application of materials on the newborn stump.
\end{abstract}

Keywords: Essential newborn care practice, Newborn

\footnotetext{
* Correspondence: yefaste2005@gmail.com

${ }^{1}$ Department of Nursing, College of Health Science and Medicine, Wolaita

Sodo University, P.O.Box: 138, Wolaita Sodo, Ethiopia

Full list of author information is available at the end of the article
}

(c) The Author(s). 2018 Open Access This article is distributed under the terms of the Creative Commons Attribution 4.0 International License (http://creativecommons.org/licenses/by/4.0/), which permits unrestricted use, distribution, and reproduction in any medium, provided you give appropriate credit to the original author(s) and the source, provide a link to the Creative Commons license, and indicate if changes were made. The Creative Commons Public Domain Dedication waiver (http://creativecommons.org/publicdomain/zero/1.0/) applies to the data made available in this article, unless otherwise stated. 


\section{Plain English summary}

Though many efforts had been made to overcome newborn mortality in Sub-Saharan Africa, it is continued to be great public health problems. Essential newborn care is a comprehensive strategy designed to improve the health of newborns through interventions before conception, during pregnancy, at and soon after birth, and in the postnatal period. Data associated with socio-demographic variables, maternal health services utilization, knowledge, counseling from a health worker, source of information, and traditional practices were collected. Even though majority of the women used boiled blade to cut the cord and tied with threads, application of butter on the umbilical stump practiced by most of the women. In addition to low coverage of initiation of breast feeding within one hour and giving colostrum, the majority, of the women in this study gave pre-lacteals. Bathing of the newborn after $24 \mathrm{~h}$ was practiced by the majority of the women. The level of coverage of essential newborn care practices in the district was generally low. The associated factors of essential newborn care practice were; ANC visit, advice about ENBC, PNC visit, residence, planned pregnancy and knowledge about newborn danger.

In conclusions; Health facilities should enhance linkage with health postse to increase antenatal and postnatal care service utilization. Health extension workers should also promote and give health education about pre-lacteal feeding, early bathing, planned pregnancy, newborn danger signs and application of materials on the newborn stump.

\section{Background}

Globally 3.1 million children die each year in their neonatal period (first 28 days of life) according to World Health Organization (WHO) 2011 report. Half of these surprisingly occur within the first $24 \mathrm{~h}$ of delivery and $75 \%$ occur in the early neonatal period ( 0 to 6 days after delivery) because of preterm births, severe infections and birth asphyxia [1]. Though many efforts had been made to overcome newborn mortality in Sub-Saharan Africa, it is continued to be great public health problems. Every year 2.9 million babies die during the neonatal period [2]; it is also the time of greatest risk for stillbirths and maternal deaths [3].

One of the targets of the MDG was a two-thirds reduction in infant and child mortality by 2015 ; it was intended to achieve by involving skilled birth attendants, increasing immunization coverage against six vaccine preventable diseases, improving the status of women through education, and enhancing women participation in the labor force [4].

Globally, around 40 million mothers give birth at home per year without any trained health worker. Factors like lack of good quality care during labor and birth; socio-economic aspects of poverty; poor health status of women; lack of autonomy and decision making authority; and illiteracy to health system related factors like poor antenatal and obstetric care; absence of trained birth attendant; inadequate referral system; lack of transportation facilities; poor linkages between health centers and communities favored the morbidities and mortalities of pregnant women, perinatal and neonate [5]. In Ethiopia, according to Ethiopia Mini Demographic Health Survey 2014 report, only $15 \%$ of births take place at a health institution, $40 \%$ of women receive Antenatal Care (ANC) from a skilled provider, and $12 \%$ of women receive a postnatal care (PNC) within the first two days of birth [6]. This favors neonatal morbidity and mortality rates to be high in Ethiopia; around 122,000 newborns die every year and the neonatal mortality rate is 37 per 1000 live births $[7,8]$.

WHO recommended Essential Newborn Care (ENBC) practices to reduce the risk of the main causes of neonatal deaths in both community and facility deliveries [8]. ENBC is a comprehensive strategy designed to improve the health of newborns through interventions before conception, during pregnancy, at and soon after birth, and in the postnatal period [9].ENBC practices, as recommended by $\mathrm{WHO}$, include drying (wiping) and wrapping the newborn immediately after birth, initiating skin-to-skin contact, dry cord care (not applying any potentially harmful substance to the umbilical cord), immediate initiation of breastfeeding and delayed bathing (for at least $6 \mathrm{~h}$ ) [10].

Ethiopia government has been striving to achieve the 3rd Sustainable Development Goal (SDG3) which is to ensure healthy lives and promote well-being for all, at all ages [11]. However, the neonatal mortality rates in Damot pulasa is still remained higher than the national level; it is 38 per 1, 000 live births [12]. Thus, new innovative strategies must be developed for safe home deliveries including essential neonatal care in order to change the practice at the household level, besides devising means of proper care of the neonate in domestic settings and ensuring proper referral of those neonates who cannot be managed at home [13]. A study showed that home-based counseling strategy using volunteers and designed for scale-up can improve newborn care behaviors in rural communities [14].

Traditional Birth Attendants (TBAs), relatives, neighbors and other aged women from the community who lack the requisite knowledge of safe delivery and newborn care practices; Meanwhile, their intervention to support mothers who give birth at home is inevitable. This may increase maternal and newborn morbidity and mortality among home delivered mothers. Traditional practice like pre-lacteal feeding, avoiding of first milk and application of material on the newborn stump was 
practiced by the majority of study participant in the study area. Therefore, improving newborn survival is a major priority in child health today and the government sets universal sustainable development goals which state to end preventable deaths of newborns and under-five children by 2030 . Therefore, this study aimed to assess selected essential newborn care practices and associated factors among home delivered mothers in Damot pulasa district.

\section{Methods and materials}

\section{Study area}

A community based cross-sectional study design was conducted from March 2016 to April 2016 in Damot Pulasa district, Wolaita zone, Southern Ethiopia. Damot Pulasa located at $365 \mathrm{Km}$ from Addis Ababa, the capital city of Ethiopia. The population of the district was estimated to be 130,515 with an estimated number of women of reproductive age group 30,818 which is $23.6 \%$ of the total population. The town has an urban kebele and 22 rural kebeles, in terms of health facilities; there are 5 governmental health centers, 8 private clinics, 1 private pharmacy, 1 drug vender and 1urban and 22 rural health posts.

\section{Populations}

The study population was randomly selected women of reproductive age group who had given birth at home in the past one year in Damot Pulasa district which encompasses 450 women who participated in the study. Those mothers who had given live birth at home within one year preceding the data collection date included in the study. The source population was list of households who had women's in the reproductive age and who had given birth at home in Damot pulasa district.

\section{Sample size determination}

The required sample size was determined by using single population proportion formula by taking $23 \%$ of expected prevalence for essential newborn care practice [8], assuming 5\% margin of error and 95\% confidence level, design effect of 1.5 and $10 \%$ for non-response rate. The calculated sample size was 450 .

\section{Sampling technique and procedures}

Cluster multi-stage sampling technique was employed for the Selection of the sampling units. In the district, there are 22 rural and an urban kebeles. From 22 rural kebeles 10 were selected by simple random sampling. The total sample size was allocated for each selected kebeles proportionally to the number of households within each kebele. Then systematic sampling technique was used to select a household where participant exist. The index case was selected and interviewed using lottery method when more than one eligible respondent present in a house.

\section{Data collection tools and procedures}

Data associated with socio-demographic variables, maternal health services utilization, knowledge, counseling from a health worker, source of information, and traditional practices were collected using interviewer administered questionnaire adapted from similar studies $[8,14,18]$ (Additional file 1). The data were collected by B.Sc. nurses who are fluent speakers of the local languages.

\section{Data processing and analysis}

Data was checked visually for completeness, and then coded and entered in to Epi Info version 3.5.1 and exported in to Statistical Program Social Science (SPSS) version 20 software for analysis. Binary and multiple logistic regressions were run to assess the associations of various factors with essential newborn care practice. The results were presented in the form of tables, figures and summary statistics. A $P$-value less than 0.05 was taken as a significant association.

\section{Results}

\section{Socio-demographiccharacterstics}

In this study, a total of 450 women have participated and the response rate was $100 \%$. In terms of religion, majority of the respondents were protestant, which accounts 238 (52.9\%) and 434 (96.4\%) were Wolaita in ethnicity. One hundred ninety-five (43.3\%) were illiterate and $310(68.9 \%)$ were housewife. With regard to marital status and place of residence, 444 (98.7\%) were married and 393 (87.3\%) were rural dweller (Table 1).

\section{Maternal health services}

A total of $364(80.9 \%)$ of respondents belonged to the age group 19-41 years and the mean age of respondents was 30.8 ( \pm 4.05$)$. Majority of the study subjects conceived their last baby unintentionally, which accounts 383 (85.1\%). Thirty two (7.1\%) received at least one ANC visit. From all mothers, 363 (80.7\%) prepared themselves for birth. From the total study subjects, 120 (26.7\%) utilized PNC service and from these mothers, 35 (29\%) utilized the service within 7-41 days (Table 2).

\section{Health service availability}

Concerning health service availability, 318 (70.7\%) mothers had health facilities (health post)in the nearby site. Home delivered mothers mentioned the following reasons why they gave birth at home; Two hundred eighty-three (62.9\%) "Not seriously ill", 247 (54.9\%) "Had TBAs", 126 (28\%) "Unwelcoming of health workers approach" and 123 (27.3\%) "An experience of safe home delivery before" Moreover, the majority of women 
Table 1 Socio-demographic characteristics of the respondent in Damot pulasa district, Wolaita Zone, Southern Ethiopia, 2016

\begin{tabular}{|c|c|c|}
\hline Variable & Frequency $(n=450)$ & Percentage (\%) \\
\hline \multicolumn{3}{|l|}{ Religion } \\
\hline Protestant & 238 & 52.9 \\
\hline Catholic & 124 & 27.6 \\
\hline Orthodox & 76 & 16.9 \\
\hline Muslim & 12 & 2.7 \\
\hline \multicolumn{3}{|l|}{ Educational status } \\
\hline No education & 195 & 43.3 \\
\hline Primary level & 175 & 38.9 \\
\hline Secondary level & 67 & 14.9 \\
\hline Higher education & 13 & 2.9 \\
\hline \multicolumn{3}{|l|}{ Ethnic group } \\
\hline Wolaita & 434 & 96.4 \\
\hline Gammo & 8 & 1.8 \\
\hline Amhara & 7 & 1.6 \\
\hline Gurage & 1 & .2 \\
\hline \multicolumn{3}{|l|}{ Occupation } \\
\hline Housewife & 310 & 68.9 \\
\hline Farmer & 13 & 2.9 \\
\hline Merchant/Trade & 100 & 22.2 \\
\hline Daily labor & 27 & 6.0 \\
\hline \multicolumn{3}{|l|}{ Marital status } \\
\hline Married & 444 & 98.7 \\
\hline Widowed & 6 & 1.3 \\
\hline \multicolumn{3}{|l|}{ Residence } \\
\hline Urban & 57 & 12.7 \\
\hline Rural & 393 & 87.3 \\
\hline \multicolumn{3}{|c|}{ Age at current pregnancy } \\
\hline$<20$ years & 2 & 0.4 \\
\hline 20-34 years & 364 & 80.9 \\
\hline $34-49$ years & 84 & 18.7 \\
\hline \multicolumn{3}{|l|}{ Planned pregnancy } \\
\hline Yes & 67 & 14.9 \\
\hline No & 383 & 85.1 \\
\hline \multicolumn{3}{|l|}{ Parity } \\
\hline 1 & 44 & 12.8 \\
\hline $2-4$ & 194 & 56.6 \\
\hline$>=5$ & 105 & 30.6 \\
\hline
\end{tabular}

participated in this study, 356 (79.1\%) decided to deliver at home by themselves (Table 3) (Fig. 1).

\section{Knowledge of the respondents}

From the total study subjects, 417 (92.7\%) of the women had information about newborn care. Among 415
Table 2 Maternal health services of respondents, in Damot pulasa district, Wolaita Zone, Southern, Ethiopia, 2016

\begin{tabular}{|c|c|c|}
\hline Variable & Frequency $(n=450)$ & Percentage (\%) \\
\hline \multicolumn{3}{|l|}{ Receive ANC } \\
\hline Yes & 32 & 7.1 \\
\hline No & 418 & 92.9 \\
\hline \multicolumn{3}{|c|}{ Number of ANC visit } \\
\hline Once & 13 & 40.6 \\
\hline Twice & 10 & 31.25 \\
\hline Three times & 6 & 18.75 \\
\hline Four times & 3 & 9.4 \\
\hline \multicolumn{3}{|c|}{ Advice about ENBC } \\
\hline Yes & 32 & 7.1 \\
\hline No & 418 & 92.9 \\
\hline \multicolumn{3}{|c|}{ Preparation for delivery } \\
\hline Yes & 363 & 80.7 \\
\hline No & 87 & 19.3 \\
\hline \multicolumn{3}{|l|}{ Receive PNC } \\
\hline Yes & 120 & 26.7 \\
\hline No & 330 & 73.3 \\
\hline \multicolumn{3}{|c|}{ Time for frequency of PNC } \\
\hline Less than $4 \mathrm{~h}$ & 12 & 10 \\
\hline $4-23 \mathrm{~h}$ & 20 & 16.7 \\
\hline $1-2$ days & 27 & 22.5 \\
\hline 3-6 days & 26 & 21 \\
\hline 7-41 days & 35 & 29 \\
\hline
\end{tabular}

(92.2\%) women who had information about when to start breastfeeding, 141 (34\%) mothers started breastfeeding within the first one hour of birth. From all mothers, $390(86.7 \%)$ of them had knowledge about colostrum and $262(67 \%)$ mothers mentioned the importance of colostrum. Four hundred six (90.2\%) of women told that it is possible to expose the neonate for morning sunlight; In addition to this, 432 (96\%) of women mentioned that, exposing the neonate for vaccination has no problem (Table 4) (Figs. 2 and 3).

\section{Newborn care practice of the respondent}

From all mothers, 408 (90.7\%) remembered where they positioned the neonate immediately after delivery. Of all mothers, 259 (63.5\%) put their newborn baby on their abdomen immediately after delivery (Table 5).

\section{Safe cord cutting}

Almost all mothers, 434 (96.4\%) used boiled new razor blade in order to cut their newborn baby and 288 (64\%) study subjects applied butter on the cord after the cord was cut. 
Table 3 Health service utilization of respondents, in Damot pulasa district, Wolaita Zone, Southern Ethiopia, 2016

\begin{tabular}{lll}
\hline Variable & Frequency $(n=450)$ & Percentage (\%) \\
\hline $\begin{array}{lll}\text { Availability of HF } \\
\text { Yes }\end{array}$ & 450 & 100 \\
$\begin{array}{l}\text { Type of HF } \\
\text { Health post }\end{array}$ & 318 & 70.7 \\
Health center & 132 & 29.3 \\
HF provide delivery & & \\
Yes & 227 & 50.4 \\
No & 179 & 39.8 \\
I don't know & 44 & 9.8 \\
Decision for place of birth & \\
Self & 356 & 79.1 \\
Husband & 77 & 17.1 \\
Relatives & 17 & 3.8 \\
\hline
\end{tabular}

\section{Initiation of early exclusive breastfeeding}

From the total study subjects, 206 (45.8\%) initiated breastfeeding within an hour of birth. From the total of 224 (49.8\%) women who gave pre-lacteals, 218 (97.3\%) gave water and $6(2.7 \%)$ gave butter. Two hundred twenty three $(49.6 \%)$ of the respondents gave first milk to the newborn and 247 (54.9\%) mothers fed their breast greater than or equal to eight times.

\section{Thermal care (bathing time)}

From all mothers, 362 (80.4\%) mothers dried/wrapped the newborn baby. Of whom 190 (52.2\%) dried/wrapped the newborn before delivery of the placenta. One hundred sixty-six (45.6\%) mothers used a pre-prepared towel to dry/wrap up the newborn. About 294 (65.3\%) of them bathed the newborn after $24 \mathrm{~h}$. The majority of study subjects, 249 (55.3\%) mothers made skin to skin contact of mother and newborn.

\section{The prevalence of essential newborn care practices}

The prevalence of cord cutting, initiation of breastfeeding and thermal care practices were studied in this study. This study revealed that the prevalence of cord cutting, initiation of breastfeeding and thermal care practices were 434 (96.4\%), 206 (45.8\%) and 294 (65.3\%) respectively (Fig. 4).

\section{Associated factors of essential newborn care practices}

In order to determine the association of independent variables with essential newborn care practices both bivariate and multivariate analysis were used. Variables that showed association with the outcome variables in the bivariate analysis were selected for multivariate analysis.

Crude analysis revealed that variables like ANC visit (COR 0.213, 95\% CI: 0.102-0.446), advice about ENBC (COR 0.166, 95\% CI: 0.078-0.354), PNC visit (COR0.135,95\% CI:0.083-0.217), place of residence (COR2.244, 95\% CI:1.251-4.025), planned pregnancy (COR 6.863, 95\% CI: 3.943-11.943), birth preparedness (COR 3.511, 95\% CI: 1.635-7.541), knowledge about newborn danger signs (COR 5.276, 95\% CI: 2.232-12.471), and knowledge about newborn care (COR 1.892, 95\% CI: 1.223-2.928) were felt to be the key predictors of essential

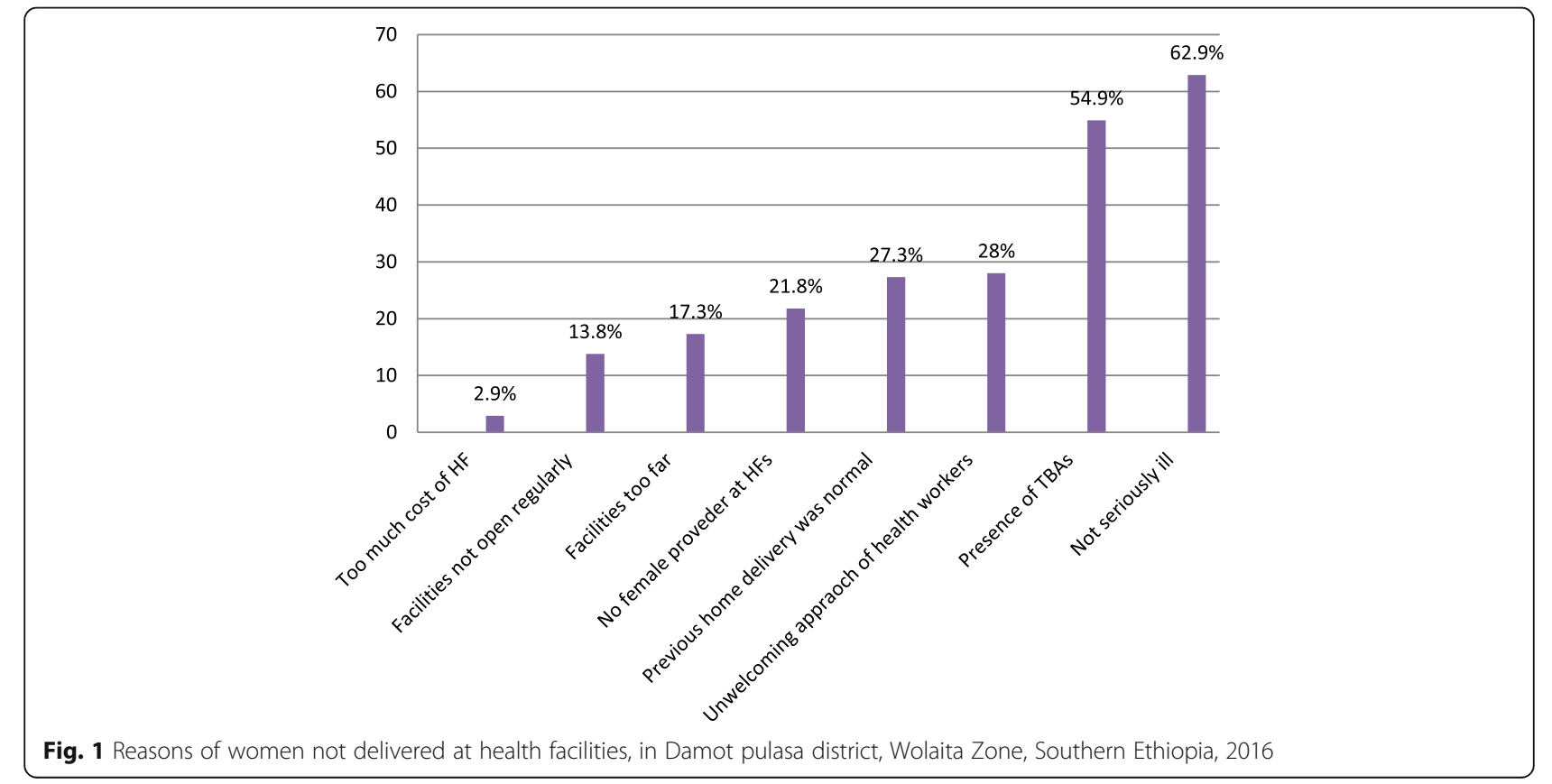


Table 4 Knowledge of the respondents, in Damot pulasa district, Wolaita Zone, Southern Ethiopia, 2016

\begin{tabular}{|c|c|c|}
\hline Variable & Frequency $(n=450)$ & Percentage (\%) \\
\hline \multicolumn{3}{|c|}{ Information on newborn care } \\
\hline Yes & 417 & 92.7 \\
\hline No & 33 & 7.3 \\
\hline \multicolumn{3}{|c|}{ Information to start breastfeeding } \\
\hline Yes & 415 & 92.2 \\
\hline No & 35 & 7.8 \\
\hline \multicolumn{3}{|c|}{ Time to start breastfeeding } \\
\hline First one hour & 141 & 34.0 \\
\hline After one hour & 274 & 66.0 \\
\hline \multicolumn{3}{|c|}{ Knowledge on first milk } \\
\hline Yes & 390 & 86.7 \\
\hline No & 60 & 13.3 \\
\hline \multicolumn{3}{|l|}{ Advantage of first milk } \\
\hline Advantageous & 262 & 67.0 \\
\hline Disadvantageous & 129 & 33.0 \\
\hline \multicolumn{3}{|c|}{ Expose neonate for morning sunlight } \\
\hline Yes & 406 & 90.2 \\
\hline No & 44 & 9.8 \\
\hline \multicolumn{3}{|c|}{ Expose neonate for vaccination } \\
\hline Yes & 432 & 96.0 \\
\hline No & 18 & 4.0 \\
\hline \multicolumn{3}{|c|}{ Information when to bath the neonate } \\
\hline Yes & 436 & 96.9 \\
\hline No & 14 & 3.1 \\
\hline \multicolumn{3}{|l|}{ Time of bathing } \\
\hline First $24 \mathrm{~h}$ & 303 & 69.5 \\
\hline After $24 \mathrm{~h}$ & 133 & 30.5 \\
\hline \multicolumn{3}{|c|}{ Knowledge about neonatal problems } \\
\hline Good knowledge & 87 & 19.3 \\
\hline Poor knowledge & 363 & 80.7 \\
\hline
\end{tabular}

newborn care practice and were used to form multivariable logistic regression analysis (Table 6).

Multivariate logistic regression was done for variables that had statistically significant association with essential newborn care practice in crude analysis. Multivariate logistic regression analysis revealed that variables like ANC visit (AOR 0.264, 95\% CI:0.090-0.773), advice about essential newborn care practice (AOR 0.114, 95\% CI:0.058-0.221), PNC visit (AOR 0.209, 95\% CI:0.1100.399), place of residence (AOR 2, 95\% CI:1.024-3.693), planned pregnancy (AOR 7, 95\% CI:3.732-11.813), and knowledge about newborn danger signs (AOR 0.277, 95\% CI:0.110-0.697) were the independent predictors of essential newborn care practice after controlling the potential confounders (Table 6).

\section{Discussion}

Generally, in this study the coverage of essential newborn care practice was low. Even though majority of the women used boiled blade to cut the cord (96.4\%) and tied with threads (98.2\%), application of butter on the umbilical stump (64\%) of the women practiced. I $n$ addition to low coverage of initiation of breast feeding within one hour (45.8\%) and giving colostrums (49.6\%),the majority, (49.8\%) of the women in this study gave pre-lacteals. Bathing of the newborn after $24 \mathrm{~h}$ was practiced by the majority (65.3\%) of the women.

The prevalence of ENBC practice was $24 \%$ which was higher than the research done in Awebel district East Gojam Zone [8] which was $23.1 \%$ but which was much lower than the study conducted in Northwest Ethiopia, Mandura district [15] which was $41 \%$. Cord cutting was practiced by the majority $96.4 \%$ of the women, using new blade, which was much higher than the study conducted in, Nawalparasi district of Nepal (48.31\%) [16], Northern Ghana which revealed 90.8\% [17], Sub urban areas of western Nigeria (90.3\%) [18], study conducted in Northwest Ethiopia, Mandura district was (59.8\%) [15], and the study conducted in four regions of Ethiopia which was $88.3 \%$ [6], the reason for this might be good awareness and custom followed in the study area but the finding was in line with the study conducted at Awebel district, East Gojam of Ethiopia (97.6\%) [8]. Majority of the study participants $(98.2 \%)$ the cord was tied with thread which was higher than the study conducted in the four regions of Ethiopia (48.5\%) [6], this might be due to awareness in the study community. Even though majority of the women used boiled blade to cut the cord and tied with threads, application of butter on the umbilical stump (64\%) of the women practiced in the study area which is higher than the study conducted in Northern Ghana (14.4\%) and the study conducted in Northwest Ethiopia Mandura district was (18.18\%) $[15,17]$ but which was lower than the study conducted in the four regions of Ethiopia (88.3\%) [6].

Initiation of breastfeeding within one hour in the study area was $45.8 \%$ which was higher than the study conducted in rural Bangladesh (40\%), East Gojam of Ethiopia (41.6\%). This finding was not incongruent with the study conducted in India (65\%), Nepal (51.3\%), Northern Ghana (80\%), Eastern Uganda (50\%), Western Nigeria (65.3\%), four regions of Ethiopia (52.1\%), Northwest Ethiopia and Southwest Ethiopia (50\%) [6, 15-21] respectively. The Majority, $49.8 \%$ of the women in this study gave pre-lacteals. The finding was higher as compared to study conducted in the four regions of Ethiopia (12.4\%) gave pre-lacteals [6], but lower than the study conducted in East Gojam of Ethiopia Awebel district, $11.2 \%$ gave pre-lacteals [8]. The reason might be traditional beliefs of the community. Breastfeeding of the 


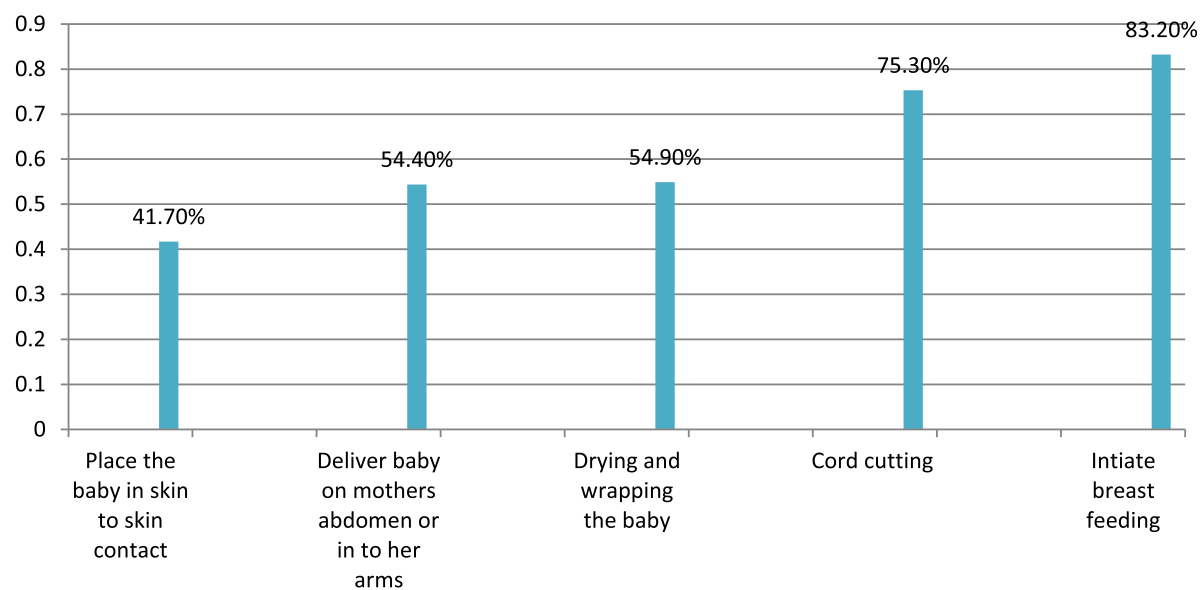

Fig. 2 Knowledge of women about ENBC practices in Damot pulasa district, Wolaita Zone, Southern Ethiopia, 2016

first milk (colostrum) was given (49.6\%) of the women in the study area. This is lower than a case study of tribal women, Gujarat (63\%) [22]. The reason for this was (33\%) of the respondent believed that first milk was disadvantageous and from this (31\%) believed that it would cause diarrhea, $(60.5 \%)$ constipation and $(58.9 \%)$ believed that it would decrease the growth of the newborn.

Bathing of the newborn after $24 \mathrm{~h}$ was practiced by the majority $(65.3 \%)$ of the women in the study area which was in line with the study conducted in East Gojam of Ethiopia, Awebel district (65.6\%) [8]. But this finding was lower than study conducted in Northern Ghana (93.6\%), Rural Nepal (72.2\%), South Sudan (99\%), Easter Uganda (100\%), Western Nigeria (98.2\%), study conducted in four regions of Ethiopia $(74.7 \%)[6,16-18,20,23]$.

In this study women who didn't get ANC visit were 73.6\% less likely to practiced essential newborn care practice as compared to those who initiated ANC visit (AOR $=0.213, P=0.015, \mathrm{CI}=0.102-0.446)$, which is supported by the study conducted in Northern Ghana which suggested that women who initiated ANC visit were two times more likely to practiced essential newborn care practice as compared to women who initiated ANC visit late [17]. This might be due to women who attended ANC have the chance of getting information about the components and the importance of newborn care practice from health care providers.

The finding of this study also showed that women who didn't get PNC visit early were $79 \%$ less likely practiced ENBC when compared to women who didn't get immediate $\mathrm{PNC}$ visit $(\mathrm{AOR}=0.209, P=0.00, \mathrm{CI}=0.110-0.399)$. This finding was supported by the study conducted in rural communities of Awebel district, East Gojam of Ethiopia, which stated that immediate PNC visit was statistically significant with ENBC practice of women and those women who had got immediate PNC visit after delivery were 3.2 times more likely to practice ENBC when compared with those who had not got immediate PNC after delivery [8]. This could be health extension workers

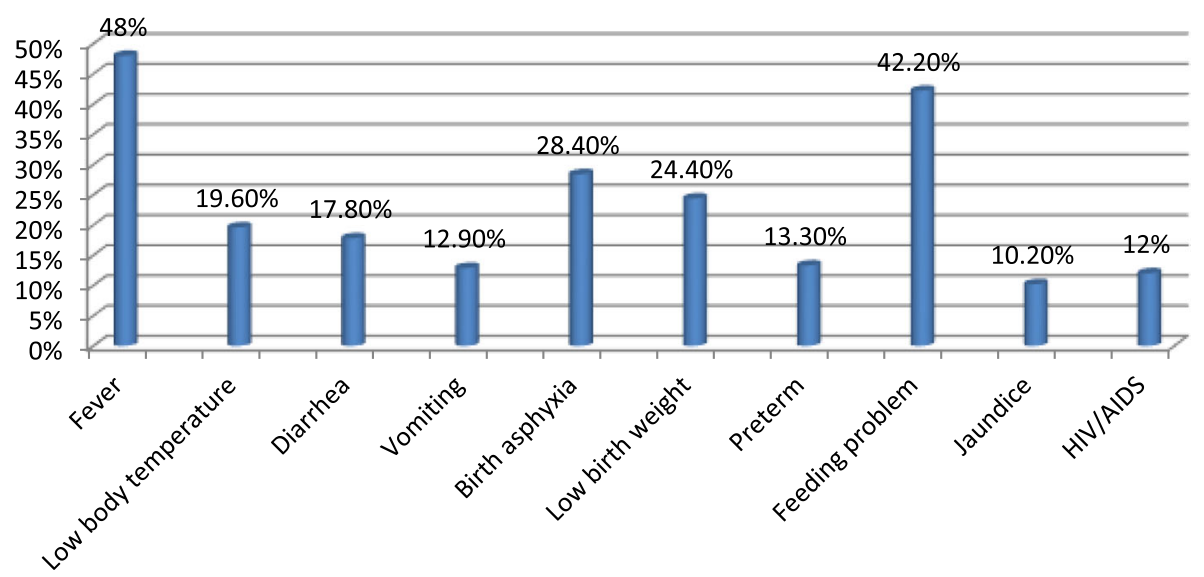

Fig. 3 Knowledge of women on newborn danger signs in Damot pulasa district, Wolaita Zone, Southern Ethiopia, 2016 
Table 5 Newborn care practices of respondents, in Damot pulasa district, Wolaita Zone, Southern Ethiopia, 2016

\begin{tabular}{|c|c|c|c|c|c|}
\hline \multirow[t]{2}{*}{ Variable } & \multirow{2}{*}{$\begin{array}{l}\text { Frequency } \\
(n=450)\end{array}$} & \multirow{2}{*}{$\begin{array}{l}\text { Percentage } \\
(\%)\end{array}$} & \multicolumn{3}{|c|}{ (Continued) } \\
\hline & & & \multirow[t]{2}{*}{ Variable } & \multirow{2}{*}{$\begin{array}{l}\text { Frequency } \\
(n=450)\end{array}$} & \multirow{2}{*}{$\begin{array}{l}\text { Percentage } \\
(\%)\end{array}$} \\
\hline Position the neonate & & & & & \\
\hline Yes & 408 & 90.7 & Water & 218 & 97.3 \\
\hline No & 42 & 9.3 & Butter & 6 & 2.7 \\
\hline Place of positioning the neonate & & & Give first milk & & \\
\hline On the mother's abdomen & 259 & 63.5 & Yes & 223 & 49.6 \\
\hline Near the delivery surface & 86 & 21.1 & No & 227 & 50.4 \\
\hline On another bed separately & 52 & 12.7 & Frequency of breastfeeding & & \\
\hline Transferred to father/relatives & 9 & 2.2 & $<8$ times & 203 & 45.1 \\
\hline I don't remember & 2 & .5 & $>=8$ times & 247 & 54.9 \\
\hline Dry/wrapping the neonate & & & Remember time of bathing & & \\
\hline Yes & 362 & 80.4 & Yes & 442 & 98.2 \\
\hline No & 88 & 19.6 & No & 8 & 1.8 \\
\hline Time of dry/wrap the neonate & & & Time of bathing & & \\
\hline Before delivery of placenta & 190 & 52.2 & First $24 \mathrm{~h}$ & 156 & 34.7 \\
\hline Immediately after delivery of placenta & 169 & 46.4 & After $24 \mathrm{~h}$ & 294 & 65.3 \\
\hline I did not remember & 5 & 1.4 & Skin to skin contact & & \\
\hline Material used for dry/wrap the neonate & & & Yes & 249 & 55.3 \\
\hline Pre-prepared towel & 166 & 45.6 & No & 201 & 44.7 \\
\hline
\end{tabular}

Piece of blanket/Gabi

Available material

Material used to cut the cord

Boiled /un-boiled new razor blade

Used razor blade

Remember material used to tie the cord

Yes

No

Material used to tie the cord

Thread

Apply material after cord cutting

Yes

No

Type of material applied on the cord

Butter

Initiate exclusive breastfeeding

Yes

No

Time of initiating exclusive breastfeeding

First one hour

After one hour

Give pre lacteals

Yes

No

226

19.8

34.6

96.4

3.6

98.2

1.8

64.0

36.0

100

50.2

49.8

Pre-lacteals given
Table 5 Newborn care practices of respondents, in Damot pulasa district, Wolaita Zone, Southern Ethiopia, 2016 (Continued)

and community health workers might gave proper advice about essential newborn care practice.

Those mothers who had got ENBC advice during ANC visit or other meetings were $83.4 \%$ more likely practiced ENBC practice as compared to women who did not got the advice (AOR $=0.114, P=0.0001, \mathrm{CI}=0.058-0.221)$. It was supported by study done, Awebel district which showed that women who had got advice about ENBC practices during monthly pregnant mothers' group meeting were 4.8 times more likely to practice ENBC as compared with those women who had not got advice about ENBC practices during monthly meeting [8]. The reason could be the health care providers could discuss about essential newborn care practice during ANC visit.

In this study, urban areas women were two times more likely practiced ENBC practice when compared to rural areas women $(\mathrm{AOR}=2, P=0.042, \mathrm{CI}=1.024-3.693)$. The finding was supported by a study conducted in Mandura district which stated that women in urban areas were three times more likely to have good newborn care practices as compared to rural areas [15]. This might be due to accessibilities of health service and good knowledge secondary to better educational status of urban women when compared to rural areas women.

Those women who planned there pregnancy were seven times more likely practiced newborn care when compared to women who did not plan their pregnancy (AOR $=7, P=0.00, \mathrm{CI}=3.732-11.813)$. The reason for 


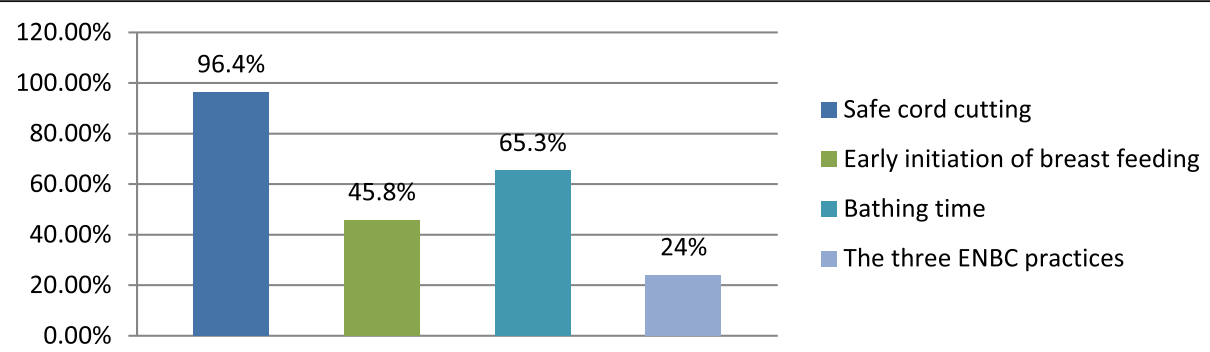

Fig. 4 Distribution of the three essential newborn care practices, in Damot pulasa district, Wolaita Zone, Southern Ethiopia, 2016

this could be women who had planned pregnancy might be more likely to use maternal and child health services.

The study showed that those women who were knowledge about newborn danger signs practiced ENBC 72\% more likely when compared to women who had poor knowledge about newborn danger signs $(\mathrm{AOR}=0.277, P$ $=0.006, \mathrm{CI}=0.110-0.697)$. This finding was supported by the study conducted in rural areas of Northern Ghana which states that women who could mention at least four danger signs of the neonates were four times more likely to give good neonatal feeding to their babies [17]. This could be most of the women in the sample may not have adequate knowledge about newborn care. This might be due to majority of the women did not get an adequate message about newborn care during antenatal care follow up. Findings in this study should be interpreted in the light of the inherent limitations of the study. Recall bias was a possibility since the women were

Table 6 Factors associated with the three essential newborn care practices by bivariate and multiple logistic analyses in Damot pulasa district, Wolaita Zone, Southern Ethiopia, 2016

\begin{tabular}{|c|c|c|c|c|}
\hline \multirow[t]{2}{*}{ Variable } & \multicolumn{2}{|l|}{ ENBCP } & \multirow[t]{2}{*}{ COR } & \multirow[t]{2}{*}{ AOR } \\
\hline & Yes (\%) & No (\%) & & \\
\hline \multicolumn{5}{|l|}{ Receive ANC } \\
\hline Yes & 18 & 14 & 1 & 1 \\
\hline No & 90 & 328 & $0.213(0.102-0.446)$ & $0.264(0.090-0.773)^{*}$ \\
\hline \multicolumn{5}{|l|}{ Advice about ENBC } \\
\hline Yes & 19 & 13 & 1 & 1 \\
\hline No & 61 & 252 & $0.166(0.078-0.354)$ & $0.114(0.058-0.221)^{*}$ \\
\hline \multicolumn{5}{|l|}{ Receive PNC } \\
\hline Yes & 64 & 56 & 1 & 1 \\
\hline No & 44 & 286 & $0.135(0.083-0.217)$ & $0.209(0.110-0.399)^{*}$ \\
\hline \multicolumn{5}{|l|}{ Residence } \\
\hline Urban & 22 & 35 & $2.244(1.251-4.025)$ & $2(1.024-3.693)^{*}$ \\
\hline Rural & 86 & 307 & 1 & 1 \\
\hline \multicolumn{5}{|l|}{ Planned pregnancy } \\
\hline Yes & 40 & 27 & $6.863(3.943-11.943)$ & $7(3.732-11.813)^{*}$ \\
\hline No & 68 & 315 & 1 & 1 \\
\hline \multicolumn{5}{|l|}{ Birth preparedness } \\
\hline Yes & 8 & 75 & $3.511(1.635-7.541)$ & $0.467(0.200-1.087)$ \\
\hline No & 100 & 267 & 1 & 1 \\
\hline \multicolumn{5}{|c|}{ Knowledge about newborn danger signs } \\
\hline Good knowledge & 6 & 102 & $5.276(2.232-12.471)$ & $0.277(0.110-0.697)^{*}$ \\
\hline Poor knowledge & 81 & 261 & 1 & 1 \\
\hline \multicolumn{5}{|c|}{ Knowledge about newborn care } \\
\hline Good knowledge & 49 & 209 & $1.892(1.223-2.928)$ & $0.760(0.460-1.257)$ \\
\hline Poor knowledge & 59 & 133 & 1 & 1 \\
\hline
\end{tabular}


inquired about events which occurred during a two year period. However, the questioning was focused on the most recent experiences of essential newborn care practices in order to minimize this possibility.

\section{Conclusions}

In this study, the level of coverage of essential newborn care practices in the district was generally low. Traditional practice like: pre-lacteal feeding, avoiding of first milk and application of material on the newborn stump were practiced by majority of study participant in the study area. This finding also revealed that most essential newborn interventions were not reaching the newborns. ANC visit, advice about ENBC, PNC visit, residence, planned pregnancy and knowledge about newborn danger signs were predictors of essential newborn care practice in the study area. Therefore Damot pulasa district health office should promote strong community based behavior change communication on the importance of ENBC practices to change the poor ENBC practices in the study area. Health facilities should enhance linkage with health posts to increase ANC and PNC service utilization. Health extension workers should promote and give health education about pre-lacteal feeding, early bathing, planned pregnancy, newborn dander signs and application of materials on the newborn stump.

\section{Additional file}

Additional file 1: Annex II: English version questionnaire. (DOCX 29 kb)

\section{Abbreviations}

ANC: Anti Natal Care; EDHS: Ethiopian Demographic and Health Survey; ENBC: Essential Newborn Care; MDG: Millennium Development Goal; NMR: Neonatal Mortality Rate; PNC: Post Natal Care; SDG: Sustainable Development Goal; SPSS: Statistical Program Social Science

\section{Acknowledgments}

We would like to thank Addis Ababa University and Wolaita Sodo University. Our gratitude also extends to Wolaita zone health department and Damot pulasa district health office for their unreserved cooperation.

\section{Funding}

Addis Ababa University.

\section{Availability of data and materials}

Data is not available for online access, however readers who wish to gain access to the data can write to the corresponding author Tesfaye Yitna Chichiabellu at yefaste2005@gmail.com.

\section{Consent to publish}

Not applicable.

\section{Authors' contributions}

TY was involved in conception, designing the study, writing proposal, analysis interpretation of data and manuscript writing. BW, AA and FH were involved in designing the study, analysis, interpretation of data and manuscript writing. All authors agreed to be accountable for all aspects of the work.

\section{Competing interest}

We declared no financial, personal or professional competing interests influenced this paper.

\section{Authors Information \\ ${ }^{1}$ Lecturer in Department of Nursing, College of Health Science and Medicine, Wolaita Sodo University. \\ ${ }^{2}$ Lecturer in Department of Nursing, School of nursing and midwifery, Addis Ababa University, \\ ${ }^{3}$ Assistant Professor in School of Public Health, College of Medicine and Health Science, Hawassa University. \\ ${ }^{4}$ Lecturer in Department of Nursing, College of Health Science and Medicine, Wolaita Sodo University. \\ ${ }^{5}$ Lecturer in Department of Medical Laboratory, College of Health Science and Medicine, Wolaita Sodo University.}

Ethics approval and consent to participate

Ethical clearance was obtained from Addis Ababa University College of Health Science Department of Nursing and Midwifery Institutional Review Board (IRB). Official letter was received from the department of nursing and midwifery and submitted to Damot Pulasa district Health office and letter of permission was taken from Damot pulasa district health office for each selected kebele to implement the study. Written informed consent was obtained from each respondent before the interview. The consent forms addressed issues relating to confidentiality and autonomy of the respondent during data collection.

\section{Publisher's Note}

Springer Nature remains neutral with regard to jurisdictional claims in published maps and institutional affiliations.

\section{Author details}

${ }^{1}$ Department of Nursing, College of Health Science and Medicine, Wolaita Sodo University, P.O.Box: 138, Wolaita Sodo, Ethiopia. ${ }^{2}$ Department of Nursing, School of nursing and midwifery, Addis Ababa University, Addis Ababa, Ethiopia. ${ }^{3}$ School of Public Health, College of Medicine and Health Science, Hawassa University, Hawassa, Ethiopia. ${ }^{4}$ Department of Nursing, College of Health Science and Medicine, Wolaita Sodo University, Sodo, Ethiopia. ${ }^{5}$ Department of Medical Laboratory, College of Health Science and Medicine, Wolaita Sodo University, Sodo, Ethiopia.

Received: 1 February 2017 Accepted: 19 September 2018

Published online: 27 September 2018

\section{References}

1. $\mathrm{WHO}, \mathrm{PMNCH}$. A Global Review of the Key Interventions Related to Reproductive, Maternal, Newborn and Child Health (RMNCH). Geneva: WHO and the Partnership for Maternal Newborn \& child health (PMNCH); 2011.

2. UN Inter-agency Group for Child Mortality Estimations. Levels and trends in child mortality. In: Estimates developed by the UN inter-agency Group for Child Mortality Estimation. New York: UN IGME; 2013.

3. Pattinson R, Kerber K, Buchmann E, Friberg IK, Belizan M, Lansky S, et al. Stillbirths: how can health systems deliver for mothers and babies? Lancet. 2011;377:1610-23.

4. World Health Organization: Estimates.In State of the World's Newborns. Washington, DC: Saving Newborn Lives, Save the Children/ USA; 2001:1-49.

5. Save the Children 2014. Ending newborn deaths: Ensuring every baby survives. 2014. [https://www.savethechildren.net/sites/default/files/libraries/ ENDING-NEWBORN-DEATHS.pdf]. Accessed 3 Mar 2014

6. Callaghan-koru JA, Seifu A, Tholandi M, De G-j J, Daniel E, Rawlins B, et al. Newborn care practices at home and in health facilities in 4 regions of Ethiopia. BMC Pediatr. 2013;13(198).

7. Central Statistical Agency and ICF International. Ethiopia Demographic and Health Survey 2011. Addis Ababa, and Maryland. https://dhsprogram.com/ pubs/pdf/fr255/fr255.pdf. Accessed Mar 2014.

8. Kokebie T, et al. Community Based Essential Newborn Care Practices and Associated Factors among Women in the Rural Community of Awabel District. Int J Adv Sci Res. 2015;01(01):17-27.

9. Narayanan I, Rose M, Cordero D, Faillace S, Sanghvi T. Perinatal / neonatal essential newborn care. Virginia: Basics Support Institutionalizing Child Surviv Proj (BASICS II) United States Agency Int Dev Arlington; 2004. 
10. WHO. Pregnancy, Childbirth, Postpartum and Newborn Care: A Guide for Essential Practice. Geneva: WHO Press World Health Organization; 2006.

11. Shiff man J. Issue attention in global health: the case of newborn survival. Lancet. 2010;375:2045-9.

12. Liu L, et al. Global, regional, and national causes of child mortality: an updated systematic analysis for 2010 with time trends since 2000. Lancet. 2012;379(9832):2151-61.

13. Central Statistical Agency. Ethiopia Mini Demographic and Health Survey. Addis Ababa; 2014.

14. Penfold S, Manzi F, Mkumbo E, Temu S, Jaribu J, D Shamba D, Mshinda $H$, Cousens S, Marchant T, Tanner M, SchellenbergDandSchellenberg J. Effect of home-based counselling on newborn care practices in southern Tanzania one year after implementation: a cluster-randomised controlled trial. BMC Pediatr. 2014;14:187.

15. Tegene T, Andargie G, Nega A, Yimam K. Newborn care practice and associated factors among mothers who gave birth within one year in Mandura District, Northwest Ethiopia. Clinics Mother Child Health. 2015;12: 172. https://doi.org/10.4172/2090-7214.1000172.

16. Kaphle HP, Yadav DK, Neupane N, Sharma B. Newborn care practices in rural communities of Nawalparasi District, Nepal. JHAS. 2013;3(1):35-9.

17. Saaka M, Iddrisu M. Patterns and determinants of essential newborn care practices in rural areas of northern Ghana. Int J Popul Res. 2014;(5):1-10.

18. Adelaja LM. A survey of home delivery and newborn care practices among women in a suburban area of Western Nigeria. ISRN Obstet Gynecol. 2011; 2011:9.

19. Vijayalakshmi S, Patil R, Datta SS. Community-based study on newborn care practices and its determinants in rural Pondicherry,India. J Neonatal Biol. 2014;3:158. https://doi.org/10.4172/2167-0897.1000158.

20. Waiswa P, Peterson S, Tomson G, Pariyo GW. Poor newborn care practices a population based survey in eastern Uganda. BMC Pregnancy Childbirth. 2010;10:9.

21. Debelew GT, Afework MF, Yalew AW. Determinants and causes of neonatal mortality in Jimma zone, Southwest Ethiopia: a multilevel analysis of prospective follow up study. PLoS One. 2014;9(9):e107184. https://doi.org/ 10.1371/journal.pone.0107184.

22. Shah BD, Dwivedi LK. Newborn care practices: a case study of tribal women, Gujarat. Health. 2013;05(08):29-40.

23. Rosales AC, Hedrick JA, Cherian DT, Moore EC, Brown KM, Walumbe E. Essential newborn care in rural settings: the case of Warrap state in South Sudan. African Evaluation Journal. 2014;2(1) Art. \#80, 6 pages. https://doi. org/10.4102/ aej.v2i1.80.

Ready to submit your research? Choose BMC and benefit from:

- fast, convenient online submission

- thorough peer review by experienced researchers in your field

- rapid publication on acceptance

- support for research data, including large and complex data types

- gold Open Access which fosters wider collaboration and increased citations

- maximum visibility for your research: over $100 \mathrm{M}$ website views per year

At $\mathrm{BMC}$, research is always in progress.

Learn more biomedcentral.com/submissions 